\title{
NASA Requirements and Applications Environments for Electrical Power Wiring
}

Mark W. Stavnes and Ahmad N. Hammoud

Sverdrup Technology, Inc.

Lewis Research Center Group

Brook Park, Ohio

August 1992

Prepared for

Lewis Research Center

Under Contract NAS3-25266

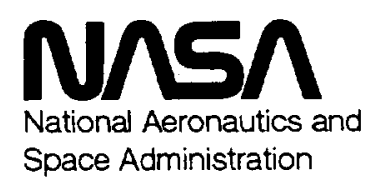

(NASA-CR-191064) NASA REQUIREMENTS

ANU APPLICATIONS ENVIRONMENTS FOR

N93-19652

ELECTRICAL POWER WIRING (SverAruP

Technology) $11 p$

Unclas 
$\cdot$
. 


\title{
NASA REQUIREMENTS AND APPLICATIONS ENVIRONMENTS FOR ELECTRICAL POWER WIRING
}

\author{
Mark W. Stavnes \\ Ahmad N. Hammoud \\ Sverdrup Technology, Inc. \\ Lewis Research Center Group \\ 2001 Aerospace Parkway \\ Brook Park, Ohio 44142
}

\begin{abstract}
Serious problems can occur from insulation failures in the wiring hamesses of aerospace vehicles. In most recorded incidents, the failures have been identified to be the result of arc tracking, the propagation of an arc along wiring bundles through degradation of insulation. Propagation of the arc can lead to the loss of the entire wiring hamess and the functions which it supports. While an extensive database of testing for arc track resistant wire insulations has been developed for aircraft applications, the counterpart requirements for spacecraft are very limited. This paper presents the electrical, thermal, mechanical, chemical, and operational requirements for specification and testing of candidate wiring systems for spacecraft applications.
\end{abstract}

\section{INTRODUCTION}

A program has been initiated by the NASA Office of Safety and Mission Quality, Technical Standards Division to identify and characterize wiring systems for aerospace vehicles. Through the NASA Lewis Research Center, information and guidance needed to develop and qualify lightweight, safe, and reliable wiring systems with new wiring insulation constructions which are arc track resistant and spacecraft suitable will be determined. Ultimately, new guidelines for wiring system development will be issued.

To facilitate the acceptance of these guidelines throughout the aerospace community, a high level of participation in the program will be maintained. The input of other NASA centers, Department of Defense laboratories, industry and academia has been solicited in the initial phases of the program, and a high level of involvement will continue during future testing and analysis.

An extensive database of testing information has been compiled for aircraft wiring systems, identifying the materials and wiring constructions which are resistant to arc tracking. However, the environment, and therefore the insulation requirements, may be significantly different for the NASA aerospace applications. These include wiring systems which must operate in Earth orbiting satellites, inside pressurized modules, on the lunar and martian surfaces, and in trans-atmospheric applications such as the Space Shuttle and other launch vehicles. The NASA program is intended to extend the testing database, based on the results of the Air Force and other related studies, to include the effects of the NASA mission environments. In this paper, the application environments and the testing requirements of the wiring systems for the different space missions will be presented.

\section{BACKGROUND}

Electrical wiring system failures have resulted in the loss of both mission and lives for NASA, the Navy, and the Air Force. Some of the NASA missions which have encountered such failures are shown below in Table 1.

One of the failure mechanisms which has been recently identified is arc tracking, which results when the insulation becomes conductive upon arc initiation. Specific instances have involved wiring systems using MIL-W-81381 (Kapton polyimide) type of insulation. Insulation degradation, such as chafing or cracking, can result in electrical arcing from a live wire through the insulation to ground, or to an adjacent wire with different potential, as shown in Figure 1. The heat caused by the arc results in pyrolysis of the polyimide film as shown in Figure 2. The pyrolized film forms a conductive path of carbon residue, allowing the arc to propagate along the wire (Figure 3 ). In some cases, the conductive carbon arc track has a high enough resistance that the current is limited, consequently the fault may not be detected by a circuit breaker. As a result, once the arc starts, there may be no protection against propagation along the wire or from "flashover" to adjacent wires as depicted in Figure 4, resulting in the loss of an entire wiring hamess.

Kapton (as been the most common material used as wiring insulation in aerospace applications due to its high dielectric strength, low weight, non-flammability, good thermal properties, and high abrasion resistance. However, it has been reported that Kapton may undergo some degradation when exposed to certain operational environments, resulting in a reduction of the insulating properties [2,3].

Table 1. Space Missions with Electrical Wiring System Failures [1 - 4]

\begin{tabular}{|l|l|l|}
\hline Mission & Cause & Result \\
\hline Gernini 8 & Electrical Wiring Short & Shorened Mission \\
\hline Apollo 204 & Damaged Insulation, Electrical Spark, 100\% $\mathrm{O}_{2}$ & Fire, 3 Astronauts Lost \\
\hline Apollo 13 & Over-voltage & Oxygen Tank Explosion, Mission Incomplete \\
\hline STS - 6 & Abrasion of Insulation/Arc Tracking & Wire Smoldering, 6 Conductors Melted \\
\hline STS - 28 & Arc Tracking & Teleprinter Cable Smoldering \\
\hline Magellan & Wrong Wiring Connection, Wiring Short & Wiring Fire During Ground Processing \\
\hline Spacelab & Damaged Insulation/Arc Tracking & Wiring Fire During Maintenance \\
\hline
\end{tabular}


Figure 1. Initiation of an Electrical Arc

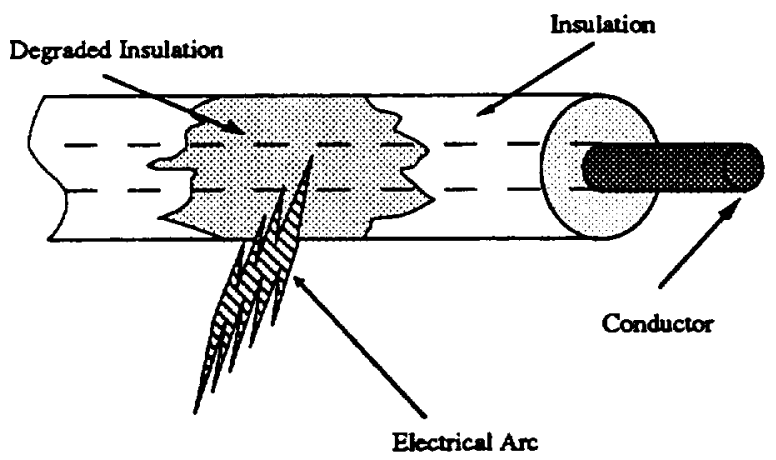

Figure 3. Carbon Arc Tracking

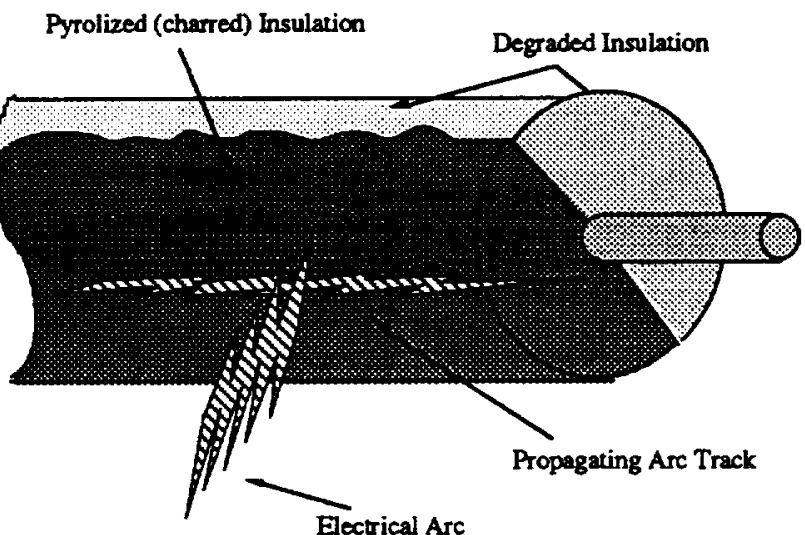

\section{CANDIDATE WIRING CONSTRUCTIONS}

The NASA wiring program is an extension of a testing program performed from 1989 to 1991 by McDonnell Aircraft Company for the Air Force's Wright Research and Development Center (WRDC). The objective of the test program was to analyze new candidate wiring constructions for use in an aircraft environment. Initially, ten insulation candidates and two baseline constructions MIL-W-81381 (Kaptone) and MIL-W22759 (cross-linked ETFE) were evaluated using relevant screening tests. The four best performing candidates as well as the baseline constructions were subjected to further full performance evaluation. The general characteristics of the insulation constructions are shown in Table 2.

The top three candidates of the Air Force Program were the Filotex, Tensolite, and Thermatics wiring constructions. These wires exhibited better flexibility, arc tracking resistance, and temperature capabilities than Kaptone [5]. However, the mechanical properties were not as good. Compared to the crosslinked ETFE, they had superior mechanical and flammability properties, but were less flexible [5]. The applicability of the Air Force test program data to the NASA applications requirements will be determined in the NASA testing program.

\section{NASA APPLICATIONS REOUIREMENTS}

The effects of the space environments and spacecraft operational conditions on the insulations of the wiring systems depend on the severity of the conditions, the spacecraft design, and the type of insulation. The actual wiring systems of the
Figure 2. Pyrolization of Insulation

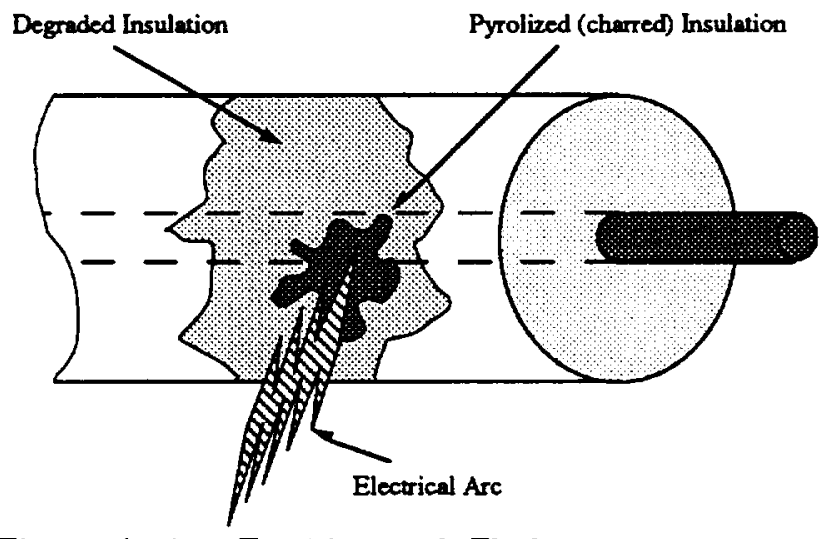

Figure 4. Arc Tracking and Flashover

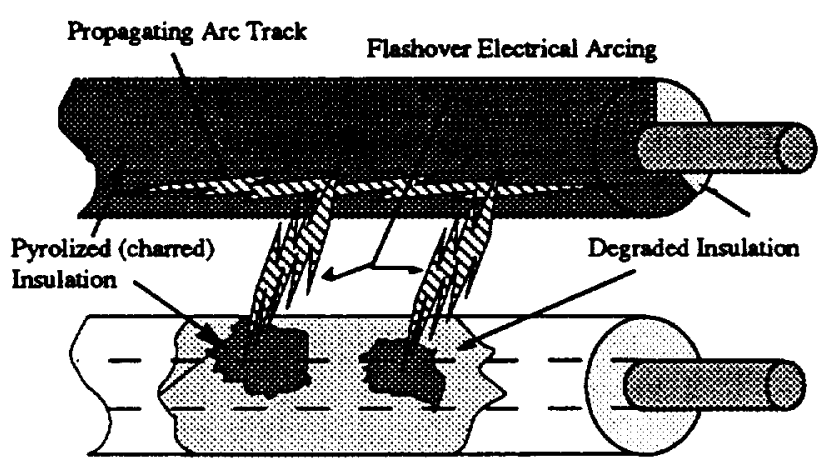

spacecraft will simultaneously encounter electrical, thermal, mechanical, chemical, environmental, and other operational stresses which may affect the performance of the insulations. Such multi-stress environments depend on the type of mission and its duration. The specific operational conditions which will exist for the NASA pressurized modules, low Earth orbit (LEO) and geosynchronous Earth orbit (GEO) spacecraft, transatmospheric vehicles, and lunar and martian surface assets will be addressed.

\section{Electrical Requirements}

The wiring systems of future spacecraft will have greater voltage and power requirements, and may involve both $A C$ and $D C$ systems. The vast majority of the power systems designed for space to date have been low voltage DC systems with power levels ranging from a few Watts to a few Kilowatts. The electrical requirements expected for the NASA missions are shown in Table 3.

A prime example of increasing power requirements is the Space Station Freedom, which distributes power up to $160 \mathrm{~V}$ at the solar array down to $28 \mathrm{~V}$ at the end loads. Previously, the majority of the power systems have been all $28 \mathrm{~V} \mathrm{DC}$. In addition, the baseline power requirements of the space station are $56.25 \mathrm{~kW}$ supplied from three $18.75 \mathrm{~kW}$ solar modules [6]. The highest power level flown to date was the $8 \mathrm{~kW}$ Skylab power system, while the majority have been less than $1 \mathrm{~kW}$ $[12,16]$. As the power systems continue to become both electrically and physically larger, such as for a permanently manned lunar or martian outpost, they will begin to have many 
Table 2. Description of Insulation Constructions [5]

\begin{tabular}{|c|c|c|}
\hline \multicolumn{2}{|c|}{ Insulation Construction } & Description \\
\hline \multicolumn{2}{|l|}{ M81318 } & Kapton with Polyimide Topcoat \\
\hline \multicolumn{2}{|l|}{ M22759 } & Teflon (XI-ETFE) \\
\hline \multicolumn{2}{|l|}{ Barcel \#1 } & 2919 Kapton (50\% OL) /nsintered PTFE Tape, Buttwrap \\
\hline \multicolumn{2}{|c|}{ Brand Rex $\# 1$} & XL ETFE Tape (50\% OL)/Kapion (50\% OL)/XL ETFE Tape (50\% OL) \\
\hline \multicolumn{2}{|c|}{ Champlain \#1 } & 2919 Kapton (50\% OL)/Extruded XL ETFE \\
\hline \multicolumn{2}{|l|}{ DuPont $\# 1$} & New P-FP Tape (50\% OL)/New P-FP Tape (50\% OL)/FP \\
\hline \multicolumn{2}{|l|}{ Gore \#3 } & PTFE (50\% OL)/HSCR PTFE (50\% OL) \\
\hline \multicolumn{2}{|l|}{ Filotex } & PTFE Extrusion/616 Kapton (50\% Min OL)/PTFE Dispersion \\
\hline \multicolumn{2}{|c|}{ Tensolite \#3 } & 200AJ919 (50\% Min OL)/PTFE Tape (50\% Min OL) \\
\hline \multicolumn{2}{|c|}{ Thermatics \#3 } & Modified PTFE Tape (50\% OL)/TPT Tape (50\% OL)/Mod PTFE Tape (50\% OL)/PTFE Dispersion \\
\hline \multicolumn{2}{|l|}{ NEMA $\$ 2$} & PTFE Tape/616 Kapton (50\% OL)/PTFE Tape \\
\hline \multicolumn{2}{|l|}{ NEMA $\# 3$} & 616 Kapton (45-50\% OL)/Extruded XL ETFE \\
\hline Abbreviations: & $\begin{array}{l}2919 \text { Kapton } \\
616 \text { Kapton } \\
200 \text { AJ919 } \\
\text { XL } \\
\text { ETFE } \\
\text { FEP } \\
\text { PFA } \\
\text { IPT }\end{array}$ & 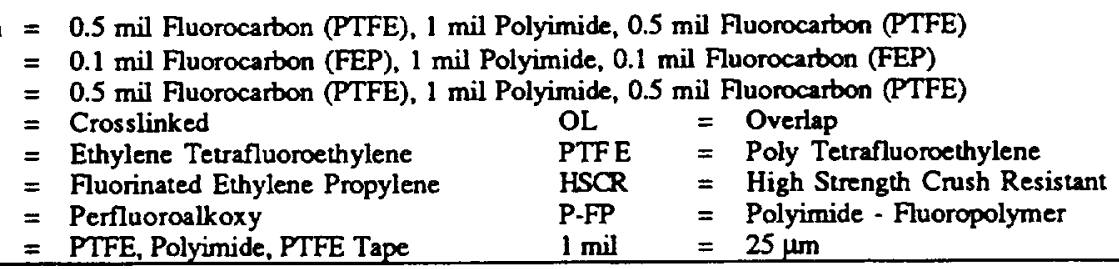 \\
\hline
\end{tabular}

Table 3. NASA Mission Electrical Requirements [6 - 15]

\begin{tabular}{|c||c|c|c|c|c|}
\hline $\begin{array}{c}\text { Mission/ } \\
\text { Reg'ts }\end{array}$ & $\begin{array}{c}\text { Press. } \\
\text { Modules }\end{array}$ & $\begin{array}{c}\text { LEO/ } \\
\text { GEO }\end{array}$ & $\begin{array}{c}\text { Trans- } \\
\text { atmospheric }\end{array}$ & $\begin{array}{c}\text { Lunar } \\
\text { Surface }\end{array}$ & $\begin{array}{c}\text { Mars } \\
\text { Surface }\end{array}$ \\
\hline Voltage & $28-120 \mathrm{~V}$ & $28-160 \mathrm{~V}$ & $28-270 \mathrm{~V}$ & $28-160 \mathrm{~V}$ & $28-160 \mathrm{~V}$ \\
\hline Frequency & $\mathrm{DC}$ & $\mathrm{DC}$ & $\mathrm{DC}$ & DC/AC & DC/AC \\
\hline Power & $75 \mathrm{~kW}$ & 10 's W $\Rightarrow 10 \mathrm{skW}$ & $\leq 7 \mathrm{~kW}$ & $50 \mathrm{~kW}$ & $20 \mathrm{~kW}$ \\
\hline
\end{tabular}

of the characteristics of terrestrial utility power systems. As a result, $A C$ systems ranging in frequency from $400 \mathrm{~Hz}$ to $20 \mathrm{kHz}$, which have been proposed for such systems, may be used.

As the operating levels of the power systems become more extreme, the electrical stresses which can lead to system failure increase. For example, when system voltage level is increased. the possibility of corona, and thus arc tracking, will increase. Tests performed at the NASA White Sands Test Facility have shown arc tracking can occur at $28 \mathrm{~V} \mathrm{DC}$, and will occur for all the samples tested at $270 \mathrm{~V}$ DC $[5,17]$. In addition, tests performed at the NASA Lewis Research Center have shown that arc tracking can occur in the Space Station Freedom Flexible Current Carrier (FCC) of the Solar Arrays [18].

\section{Thermal Requirements}

In many cases the space environment, because of the lack of significant atmosphere, presents an extreme thermal stress on the wiring systems. Both hot and cold temperature extremes result because there is no atmosphere to contain the heat when not exposed to the Sun, or to block the exposure of direct sunlight. Additionally, when the wires are protected from the temperature extremes, such as in a manned pressurized module, the enriched oxygen environment may increase the likelihood of a fure resulting from a wiring failure. The expected thermal environments for the NASA missions are shown in Table 4.

Under temperanre extremes, the effects of aging may be accelerated and can cause embrittlement. In addition, cycling under these conditions, as a result of the repeated tensile and compressive forces which react against connectors, and the repeated creasing and stretching which will occur in the same place each cycle due to the "memory" of the polymer, will eventually lead to insulation failure [22].

The wiring systems for the NASA missions will all encounter wide temperature extremes, except for the interior of the pressurized modules which will be temperature regulated. The major factor differentiating the severity of the cases is the frequency of the thermal cycling which will occur. For the LEO and GEO satellites, the thermal cycling is dependent upon the altitude. For a typical $550 \mathrm{~km}$ low Earth orbit, there will be about 15 eclipse cycles every day, while at geosynchronous 
Table 4. NASA Mission Thermal Requirements [7,19 - 25]

\begin{tabular}{|c|c|c|c|c|c|}
\hline $\begin{array}{c}\text { Mission/ } \\
\text { Reg'ts }\end{array}$ & $\begin{array}{l}\text { Press. } \\
\text { Modules }\end{array}$ & $\begin{array}{l}\text { LEOY } \\
\text { GEO }\end{array}$ & $\begin{array}{c}\text { Trans- } \\
\text { atmospheric }\end{array}$ & $\begin{array}{l}\text { Lumar } \\
\text { Surface }\end{array}$ & $\begin{array}{l}\text { Mars } \\
\text { Surface }\end{array}$ \\
\hline $\begin{array}{l}\text { Temperature/ } \\
\text { Thermal Cycling } \\
\text { (C) }\end{array}$ & $15 \Rightarrow 25$ & $\begin{array}{c}\text { LEO: }-65 \Rightarrow 120 \\
6000 / \mathrm{yr} \\
\text { GEO: }-196 \Rightarrow 12890 / \mathrm{yr}\end{array}$ & $\begin{array}{c}-200 \Rightarrow 260 \\
\text { up to } 6000 / y r \\
\text { of on-orbit operation }\end{array}$ & $\begin{array}{c}-171 \Rightarrow 111 \\
13 / \mathrm{yr}\end{array}$ & $\begin{array}{c}-143 \Rightarrow 27 \\
356 / y r\end{array}$ \\
\hline $\begin{array}{c}\text { Flammability } \\
\text { Toxicity }\end{array}$ & $30 \%$ Oxygen & $\mathbf{N} / \mathbf{A}$ & $0 \Rightarrow 30 \%$ Oxygen & $\mathrm{N} / \mathrm{A}$ & $0.13 \%$ Oxygen \\
\hline
\end{tabular}

Earth orbit, there will be only 90 cycles per year, with a maximum shadow of 1.2 hours per day $[23,26]$. Once again, the trans-atmospheric temperanure cycling depends on the altitude of orbit, and can experience the same frequency as LEO. However, the time in orbit is generally short term. The thermal cycling on the planetary surfaces depends upon the orbit mechanics in relationship to the Sun. For the Moon, where the Earth is also a factor, a day/night period of approximately 28 days is encountered, resulting in 13 cycles per year. A system on the surface of Mars would have to endure a day/night cycle every 24.6 hours ( 356 cycles/Earth year). However, because Mars is 1.5 times further from the Sun than Earth, the Sun's intensity is decreased by $43 \%$, this low intensity and the attenuation of the martian atmosphere limits the maximum temperature to $27^{\circ} \mathrm{C}[24]$.

Although the environments which the satellites will operate are extreme, the spacecraft design may decrease the impact of the thermal stresses on the wiring system. The wiring may be protected by the spacecraft structure from the extremes of the environment. In addition, spacecraft are designed to keep the electronics and battery systems within a comparatively narrow temperature range by radiative cooling, which in turn may protect the electrical wiring. However, for the Space Station Freedom, the temperature of the wiring enclosed in the cable trays is increased as a result of the internally generated ohmic $\left(I^{2} \mathrm{R}\right)$ losses $[20,27]$. On the planetary surfaces, cabling may be laid out directly on the surface, enduring the full range of temperature extremes.

The current database of testing results for the aircraft environment performed for the Air Force examined only a small number of cycles (4) for a temperature range of $-55^{\circ} \mathrm{C}$ to $200^{\circ} \mathrm{C}$ [5]. Testing needs to be performed to extend the results to include the high number of cycles required in the NASA mission scenarios.
Initially, Kapton was chosen as the primary insulation because it is considered to be non-flammable. However, the initiation, propagation, and burning properties of the various insulation constructions must be considered. The LEO/GEO, planetary surfaces, and expendable launch vehicles have low oxygen concentrations, and thus a fire is unlikely. Inside the pressurized modules and the space shuttle, the atmosphere will be nominally air (21\% oxygen, $101 \mathrm{kPa}$ total pressure) enriched to $30 \%$ oxygen at $69 \mathrm{kPa}$ total pressure for prebreathing prior to an extravehicular activity. The latter atmosphere can decrease ignition delay, increase flame spread rate, and increase extinguishment difficulty. The fires on board Apollo 204 and 13 were promoted by the high oxygen concentration environments [1]. In addition, the toxicity of products released during a fire and after extinguishment of a fire is an important concern, due to the enclosed environment and the long atmospheric refresh time [28].

Flammability tests were performed in the Air Force program to determine the self extinguish and flame propagation properties of the wire samples in an aircraft environment. This area of testing must be expanded to include the $30 \%$ oxygen, $69 \mathrm{kPa}$ (10 psi) pressure, and microgravity environment of the NASA missions.

\section{Mechanical Requirements}

The mechanical environment for the NASA missions includes abrasion, which can result from the vibration and acoustic noise during launch, and also the cutting and impacting which can occur from meteoroids and debris. The mechanical stress environments which the NASA missions will experience are shown in Table 5.

Abrasion will tend to cause both chafing and wire damage, which increase the possibility of arc tracking. The only significant source of vibration will be from the launch vehicle

Table 5. NASA Mission Mechanical Requirements $[7,19,21,24,25,27]$

\begin{tabular}{|c|c|c|c|c|c|}
\hline $\begin{array}{l}\text { Mission/ } \\
\text { Reg'ts } \\
\end{array}$ & $\begin{array}{c}\text { Press. } \\
\text { Modules } \\
\end{array}$ & $\begin{array}{l}\text { LEO/ } \\
\text { GBO }\end{array}$ & $\begin{array}{c}\text { Trans- } \\
\text { atmospheric }\end{array}$ & $\begin{array}{l}\text { Lunar } \\
\text { Surface }\end{array}$ & $\begin{array}{c}\text { Mars } \\
\text { Surface }\end{array}$ \\
\hline $\begin{array}{l}\text { Vibration/ } \\
\text { Acoustic } \\
\text { (Abrasion) }\end{array}$ & $\begin{array}{c}\text { launch: } 1-10 \mathrm{~g} \\
\text { Sound Pressure } \\
\text { Level : } 137-145 \mathrm{~dB}\end{array}$ & $\begin{array}{c}\text { launch: } 1-10 \mathrm{~g} \\
\text { Sound Pressure } \\
\text { Level : } 137-145 \mathrm{~dB}\end{array}$ & $\begin{array}{c}\text { launch: } 200 \mathrm{~g} \\
\text { Sound Pressure } \\
\text { Level : } 137-145 \mathrm{~dB}\end{array}$ & $\begin{array}{c}\text { launch: } 1-10 \mathrm{~g} \\
\text { Sound Pressure } \\
\text { Level : } 137-145 \mathrm{~dB}\end{array}$ & $\begin{array}{c}\text { launch: } 1-10 \mathrm{~g} \\
\text { Sound Pressure } \\
\text { Level : } 137-145 \mathrm{~dB}\end{array}$ \\
\hline $\begin{array}{l}\text { Meteoroids } \\
\text { Debris }\end{array}$ & N/A & $\begin{array}{c}11-26 \\
\text { impact/m²/yr } \\
\text { (impacts } \geq 50 \mu \mathrm{m} \text { ) }\end{array}$ & $\begin{array}{r}0-26 \mathrm{impac} / \mathrm{m}^{2} / \mathrm{yr} \\
\text { (impacts } \geq 50 \mu \mathrm{m} \text { ) }\end{array}$ & $\begin{array}{c}0.01-0.5 \text { impacts } / \mathrm{m}^{2} / \mathrm{yr} \\
(\mathrm{dm}=500 \mu \mathrm{m}) \\
1.2 \times 10^{-4} \mathrm{impact} / \mathrm{km}^{2} / \mathrm{yr} \\
\left(100^{\prime} \mathrm{gm}\right)\end{array}$ & $\begin{array}{l}\text { very low } \\
\text { probability }\end{array}$ \\
\hline
\end{tabular}


during launch and descent. Very little vibration will occur while the vehicle is in orbit. The vibration environment during launch can approach accelerations of $10 \mathrm{~g}$ at frequencies of 1000 $\mathrm{Hz}$ [27]. Portions of the launch vehicle may encounter short term vibrational forces of up to $200 \mathrm{~g}$ [7].

Vibration induced from acoustic fields may also be an important factor. The acoustical fields vary throughout the launch, peaking immediately before the launcher is released and as the speed of sound is approached due to atmospheric disturbances. The acoustic field induces a vibrational response which may actually be larger than the structurally transmitted vibration [29].

The actual effects of vibration on the wiring systems may be limited because the exposure is intense but short-lived. However, other sources of abrasion have resulted in insulation degradation in both the Space Shuttle fleet and the Spacelab module as a result of maintenance work. Precautions have been taken, such as shielding and securing the wiring, to minimize these sources of abrasion [4].

A large amount of testing has been performed for the aircraft environment on the abrasion properties of the wiring samples. The NASA vibration environment due to the launch environment is, in general, more extreme than the aircraft environment, but shorter term. Therefore, testing to determine the insulations resistance to the NASA vibration environment needs to be performed.

Meteoroids and debris may cause a threat to the wiring systems, even when less than $1 \mathrm{~mm}$ in diameter, because of their higher frequency and velocity (average $20 \mathrm{~km} / \mathrm{s}$ up to $72 \mathrm{~km} / \mathrm{s}$ ) $[21,29]$. Meteoroids and debris impacting the wiring can cause holes in the surface of the insulation and the resulting notch can lead to arc initiation. Larger pieces of debris could sever a wire, causing an open circuit.

The meteoroid and debris exposure will be at significant levels only in the LEO/GEO and lunar surface cases. The pressurized module wiring is protected by the enclosed structure, and the martian surface is shielded by its atmosphere. In LEO, the amount of debris of diameter (d) $\geq 50 \mu \mathrm{m}$ which impacts a surface ranges from 11 to $26 \mathrm{impacts} / \mathrm{m}^{2} / \mathrm{yr}$. On the Moon, the surface is bombarded by cometary debris, interstellar grains and lunar ejecta at a rate of 0.01 to 0.5 impacts $/ \mathrm{m}^{2} / \mathrm{yr}(\mathrm{d} \approx 500 \mu \mathrm{m})$. Meteoroids in the 100 gram range also will impact the surface at a rate of $1.2 \times 10^{-4} \mathrm{impacts} / \mathrm{km}^{2} / \mathrm{yr}[21,24]$.
For the most part, the wiring of the spacecraft in LEO/GEO orbits and on the surface of the Moon will be shielded by spacecraft structure from the impact of meteoroids and debris. However, for wiring which is exposed, the amount of impacts is not expected to be life limiting, although single failures can result in an increased possibility of arc tracking $[21,22]$.

A significant amount of testing was performed for the aircraft environment on properties which may be related to an insulations meteoroid and debris resistance. Tests were performed to determine the insulation resistance to cut-through. impacts, propagation of a notch, and crushing. These tests must be considered in multiple stress environments (i.e. cutthrough at high temperature), to determine the suitability of the wiring samples for space applications.

\section{Chemical Requirements}

The NASA missions may expose the wiring to significant levels of chemical environments which may result in degradation of the insulation, which can lead to arc tracking failures. Water (humidity) and other various chemicals, such as hydraulic fluid, are present in many space missions, and may be exposed to the insulations. High concentrations of both atomic oxygen and carbon dioxide may also react with the insulations. Finally, products outgassed from the insulations once in space need to be considered for both toxicity and excessive weight loss. The possible chemical environments for the NASA missions are shown in Table 6 .

Exposure to high humidities, in addition to water and high $\mathrm{pH}$ fluids, can result in hydrolysis which may reduce the strength of the insulation. The hydrolytic reaction reduces the polymer chain length causing it to be weak and brittle $[4,26]$. In general, exposure to humidity is limited for the NASA missions because the environment is regulated throughout the life of the vehicles, and once in space, sources of humidity will be scarce. The space vehicles must be assembled and stored in controlled humidity environments, and the payload fairings regulated to $\leq$ $50 \%$ relative humidity (RH). Inside the pressurized modules, although the environment is controlled, humidity may be possible due to the enclosed environment. Ar extrapolation of the current hydrolysis testing data for the space shuttle specification of $50 \%$ humidity at ambient temperature results in insulation lifetimes from 15 to 600 years. However, the lifetime will be reduced to 1 month if the exposure is raised to $100 \% \mathrm{RH}$ at $100^{\circ} \mathrm{C}$ [4]. Further analysis of the effects of the humidity environment of the NASA missions on the various wiring samples should be performed.

Table 6. NASA Mission Chemical Requirements $[3,7,19,21,24,30]$

\begin{tabular}{|c||c|c|c|c|c|}
\hline $\begin{array}{c}\text { Mission/ } \\
\text { Reg'ts }\end{array}$ & $\begin{array}{c}\text { Press. } \\
\text { Modules }\end{array}$ & $\begin{array}{c}\text { LEO/ } \\
\text { GEO }\end{array}$ & $\begin{array}{c}\text { Trans- } \\
\text { atmospheric }\end{array}$ & $\begin{array}{c}\text { Lumar } \\
\text { Surface }\end{array}$ & $\begin{array}{c}\text { Mars } \\
\text { Surface }\end{array}$ \\
\hline Humidity & $\begin{array}{c}550 \% \text { inside } \\
\text { payload fairing }\end{array}$ & $\begin{array}{c}\leq 50 \% \text { inside } \\
\text { payload fairing }\end{array}$ & $\begin{array}{c}\leq 50 \% \text { in payload fairing } \\
\leq 100 \% \text { extemal }\end{array}$ & $\begin{array}{c}\leq 50 \% \text { inside payload } \\
\text { faining }\end{array}$ & $\begin{array}{c}0.03 \% \mathrm{H}_{2} \mathrm{O} \\
100 \% \mathrm{RH} \text { at night }\end{array}$ \\
\hline $\begin{array}{c}\text { Outgassing/ } \\
\text { Toxicity }\end{array}$ & To Be Detemined & $\begin{array}{c}\text { Cating of optical } \\
\text { surfaces may cause } \\
\text { transmittance losses }\end{array}$ & $\begin{array}{c}\text { Coating of optical } \\
\text { surfaces may cause } \\
\text { transmittance losses }\end{array}$ & $\begin{array}{c}\text { Coating of optical } \\
\text { surfaces may cause } \\
\text { transmittance losses }\end{array}$ & $\begin{array}{c}\text { Coating of optical } \\
\text { surfaces may cause } \\
\text { transmittance losses }\end{array}$ \\
\hline $\begin{array}{c}\text { Gas/Fluid } \\
\text { Compatibility }\end{array}$ & $\begin{array}{c}\text { To Be Determined } \\
\text { (TBD) }\end{array}$ & $\begin{array}{c}\text { AO: } 10^{7}-10^{8} \mathrm{~cm}^{-3} \\
4.3-4.4 \mathrm{eV} \\
\text { Chemicals TBD }\end{array}$ & $\begin{array}{c}\text { Water/Salt Water/Liquid } \\
\text { Hydrogen \& Oxygen/ } \\
\text { Chemicals/Hydrazine }\end{array}$ & $\begin{array}{c}\text { Electrostatically } \\
\text { Charged Dust Particles, } \\
\text { Chemicals TBD }\end{array}$ & $\begin{array}{c}\mathrm{AO}: 10^{3}-10^{5} \mathrm{~cm}^{-3} \\
\text { Chemicals TBD }\end{array}$ \\
\hline
\end{tabular}


Exposure to atomic oxygen (AO) erodes Kapton 8 , and may affect other insulating materials [2]. The resulting weight loss reduces the thickness of the insulation, and can result in the degradation of insulating properties. Significant amounts of atomic oxygen is known to exist in low Earth orbits and around Mars. For low Earth orbits ( 400 to $500 \mathrm{~km}$ ), the atomic oxygen exposure can range from $10^{7}$ to $10^{8}$ atoms $/ \mathrm{cm}^{3}$ with an average atomic energy of 4.3 to $4.4 \mathrm{eV}[21,30]$. In the martian atmosphere, particles of atomic oxygen will exist in concentrations in the range $10^{3}$ to $10^{5}$ atoms $/ \mathrm{cm}^{3}$. In addition, the interaction of the insulations with the high concentrations of carbon dioxide (93.5\%) in the martian atmosphere may result in degradation and must be determined by testing. Build up of dust particles on lunar surface wiring is likely due to surface activities. Direct degradation of the insulation in contact with the lunar soil may not be an issue, but the secondary effects of dust accumulation must be considered. A layer of dust more than about $11 \mathrm{\mu m}$ would not only effectively block thermal radiation, but it would also limit all heat transfer to the insulation, due to the poor conductivity of the lunar soil [31].

Once in space, some outgassing of moisture or additives from the insulation will occur. Inside the pressurized modules, because of the enclosed manned environment, the toxicity of the outgassed materials must be determined by testing. In the other cases, materials outgassed to space pose no specific threat, unless the amount of outgassing is enough to significantly degrade the insulation, or if sensitive optical surfaces become coated. This can affect the transmittance properties of the coated surfaces and thereby influence the performance of optical mirrors, solar arrays, and thermal radiators.

A series of tests was performed by the Air Force to determine the effects of various fluids on the insulation samples. The electrical and physical properties of the wires were tested after immersion in lubricating oil, hydraulic fluid, coolant, gasoline, and a number of other fluids which are representative of an aircraft environment. Further testing is required to study the effects of fluids which may be exposed to the wiring systems of space vehicles.

\section{Environmental/Operational Requirements}

The NASA missions will encounter many operational conditions which are particular to the space environment, including high levels of solar radiation, low gravity and pressure, and a charged ambient plasma. In many cases, these environments will be encountered simultaneously, and as the operational lifetimes increase, may have a significant impact on the insulation performance. The expected levels of exposure of the environment and other operational factors are shown in Table 7.

The space radiation environment is composed of cosmic rays, electromagnetic radiation, $V$ an Allen belt radiation, auroral particles, and solar flare particles. The major component of electromagnetic radiation which may induce insulation degradation is ultraviolet (uv) solar radiation, which can cause color changes and embrittlement of the insulation [29]. Particulate radiation consists of electrons, protons, neutrons, alpha particles, and others. Damage to polymers which can result from particulate radiation may occur because of the removal of a bonded electron, leading to bond rupture, free radicals, and discoloration. The resulting degradation may cause a loss of mechanical strength, an increase in vapor pressure, and a reduction in molecular weight [29].

The total energy received from the Sun in orbits near the Earth is equal to 1 solar constant which is $1353 \mathrm{~W} / \mathrm{m}^{2}$ at air mass zero (AMO). The energy of the radiation is inversely proportional to the wavelength, therefore the uv radiation is higher energy than the visible or infrared, and thus more harmful to insulations. The energy of the uv radiation can be high enough to cause excitation, if not ionization in some materials. Over the whole uv wavelength range up to $0.4 \mu \mathrm{m}$, the intensity average is 123 $\mathrm{W} / \mathrm{m}^{2}$ [29]. The exposure dose of uv radiation is typically expressed in "Equivalent Sun Hours" or "ESH", which must always be associated with a wavelength band. For example, 50 hours of exposure to 2 uv solar constants in the wavelengths between 0.2 and $0.3 \mu \mathrm{m}$ is equal to "100 ESH, $0.2-0.3 \mu \mathrm{m}$ " [36].

Table 7. NASA Mission Environmental/Operational Requirements $[6,8,14,15,20,21,24,32-35]$

\begin{tabular}{|c|c|c|c|c|c|}
\hline $\begin{array}{c}\begin{array}{c}\text { Mission/ } \\
\text { Reg'ts }\end{array} \\
\end{array}$ & $\begin{array}{c}\text { Press. } \\
\text { Modules } \\
\end{array}$ & $\begin{array}{l}\text { LEO/ } \\
\text { GEO } \\
\end{array}$ & $\begin{array}{c}\text { Trans- } \\
\text { atmospheric }\end{array}$ & $\begin{array}{l}\text { Lunar } \\
\text { Surface }\end{array}$ & $\begin{array}{c}\text { Mars } \\
\text { Surface }\end{array}$ \\
\hline Radiation & N/A & $\begin{array}{c}\text { LEO uv: } 2220 \Rightarrow 5844 \\
\text { GEO uv: } 8760 \text { Equivalent Sun } \\
\text { Hours/year (ESH/yr) }\end{array}$ & $\begin{array}{c}\text { uv: } 2220 \Rightarrow 8760 \\
\text { ESH/yr }\end{array}$ & $\begin{array}{l}\text { solar: } 1371 \mathrm{~W} / \mathrm{m}^{2} \\
\text { uv: } 8760 \mathrm{ESH} / \mathrm{yr}\end{array}$ & $\begin{array}{c}\text { Solar: } 590-650 \\
\text { W/m } \\
\text { uv: } 1656 \text { ESH/yr }\end{array}$ \\
\hline Gravity & $10^{6} \Rightarrow 10^{-3} 8$ & $10^{-6} \Rightarrow 10^{-3} \mathrm{~g}$ & $10^{-6} \Rightarrow 1 \mathrm{~g}$ & $0.165 \mathrm{~g}$ & $0.38 \mathrm{~g}$ \\
\hline $\begin{array}{l}\text { Pressure } \\
(\mathbf{P a})\end{array}$ & $69 \mathrm{k} \Rightarrow 101 \mathrm{k}$ & $\begin{array}{l}\text { LEO: } 10^{-8} \Rightarrow 10^{-3} \\
\text { GEO: } 10^{-11}\end{array}$ & $10^{-11} \Rightarrow 101 k$ & $10^{10} \Rightarrow 10^{6}$ & $590 \Rightarrow 1500$ \\
\hline Plasma & N/A & $\begin{array}{c}\text { LEO: } 0.3-5 \times 10^{5} \mathrm{~cm}^{-3} \\
0.1-0.2 \mathrm{eV} \\
\text { GEO: } 0.24-1.12 \mathrm{~cm}^{-3} \\
120-295 \mathrm{keV}\end{array}$ & $\begin{array}{c}0.9 \times 10^{5} \mathrm{~cm}^{-3} \\
0.1-0.2 \mathrm{eV}\end{array}$ & $\begin{array}{l}\text { Solar Wind } \\
\text { Solar \& Galactic } \\
\text { Cosmic Rays }\end{array}$ & $\begin{array}{l}10^{3}-10^{5} \mathrm{~cm}^{-3} \\
\mathrm{O}^{+}, \mathrm{O}_{2}{ }^{4}, \mathrm{CO}_{2}^{+}\end{array}$ \\
\hline $\begin{array}{c}\text { Lifetime } \\
\text { (Ors) }\end{array}$ & 30 & $\begin{array}{l}\text { LEO: } 30 \\
\text { GEO: } 20\end{array}$ & 30 & 30 & 30 \\
\hline
\end{tabular}


The exposure to uv radiation at both GEO and on the lunar surface is approximated by the exposure at AM0, because of the lack of significant atmospheric shielding. The resulting radiation exposure per year is $8760 \mathrm{ESH}$. In lower Earth orbits, some attenuation due to the atmosphere decreases the exposure, resulting in a range of $2220 \mathrm{ESH} /$ year for a Sun sweeping satellite surface, to $5844 \mathrm{ESH} /$ year for a Sun tracking surface [21]. Mars is 1.5 times the distance of Earth from the Sun, as a result the intensity of the Sun is $43 \%$ less than at the Earth, for a yearly uv exposure of $1656 \mathrm{ESH} / \mathrm{yr}[29,36]$. The effects of exposure to these levels of uv radiation in the space environment need to be determined by testing. The lack of significant oxygen may limit the effects of oxidation, and the wiring may be shielded by the spacecraft structure. Nevertheless, continuous exposure may cause degradation, and the combined effects need to be investigated.

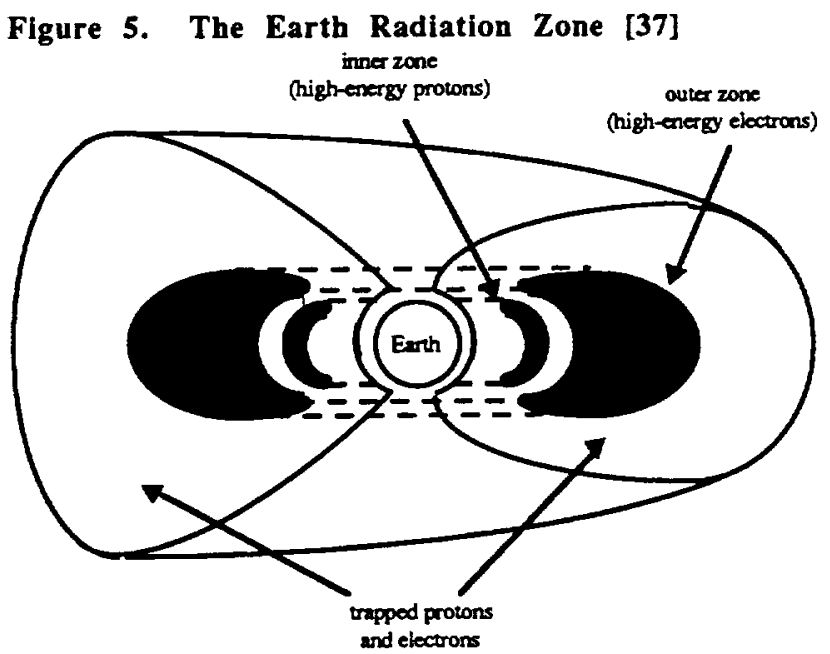

Particulate solar radiation consists primarily of protons and electrons of the solar wind. These are trapped by the Earth's magnetic field forming the $V$ an Allen belts as shown in Figure 5 .

The innerbelt consists mostly of low energy electrons (20 keV to $1 \mathrm{MeV}$ ) and high energy protons ( $\geq 600 \mathrm{MeV}$ ), and extends from about $480 \mathrm{~km}$ to $6400 \mathrm{~km}$ above the Earth. The outerbelt is mostly high energy electrons (up to $500 \mathrm{MeV}$ ) with few low energy protons $(\approx 60 \mathrm{MeV})$, and extends from $16,000 \mathrm{~km}$ to $58,000 \mathrm{~km}[29,37]$. These particles from the solar wind also make up the majority of the lunar "atmosphere". There are two other sources of ionized particles both in space and on the surface of the Moon. Solar Cosmic Rays (SCR's), which are mostly protons and $\alpha$ particles, ejected from the Sun during solar flares, and Galactic Cosmic Rays (GCR's), which are charged particles from outside the solar system consisting of $85 \%$ protons, $14 \% \alpha$ particles, and $1 \%$ heavier atoms and are the most energetic type of particulate radiation, but the concentration is low [29]. The particulate environment for the lunar surface is shown below in Table 8.

Under normal gravity conditions (1g), the air molecules present around a flame can provide cooling to a burning or overheated wire due to heat convection processes. However, in space ( $\mu \mathrm{g})$, hot air masses can remain stagnant in the area of the heat source. In the arc tracking process, the heat of an arc may not be dissipated as quickly, accelerating the pyrolysis of the insulation and the initiation of the carbon arc track [28]. The microgravity environment of the pressurized modules, LEO/GEO spacecraft, and trans-atmospheric vehicles will experience acceleration forces ranging from $10^{-6}$ to $10^{-3} \mathrm{~g}$, while the planetary surface missions will operate under gravity conditions of $0.165 \mathrm{~g}$ on the Moon and $0.38 \mathrm{~g}$ on Mars [8,24]. Characterization of the arc tracking phenomenon under these low gravity conditions must be performed.

At low pressures, weight loss as a result of evaporation of low molecular weight fraction materials, unreacted additives, contaminants, adsorbed gases, and moisture can induce changes in the properties of the insulation. For example, the loss of a plasticizer by evaporation could cause the insulation to become rigid or brittle [29]. In addition, decreased pressure lowers the voltage level for which the inception of corona can occur. Except for the inside of the pressurized modules which are regulated at constant pressures of 69 to $101 \mathrm{kPa}$ (10 to 14.7 psi), the wiring systems will operate in low pressure environments approaching complete vacuum. The Mars atmospheric pressure varies with the seasons from 590 to 1500 $\mathrm{Pa}$, while the Earth orbiting and lunar surface cases are essentially devoid of any atmosphere, and range from $10^{-3} \mathrm{~Pa}$ (LEO) to the interplanetary value of $10^{-11} \mathrm{~Pa}[24,32,33]$. The effects of low pressure on the inception and propagation of arc tracking must be considered in the testing program.

In a charged plasma environment, potentials between spacecraft surfaces and the ambient plasma can build up and lead to electrical arcing. The transient generated by this discharge can couple into the spacecraft electronics and may cause upsets ranging from logic switching to complete system failure. Discharges also can enhance surface contamination and cause long term degradation [35]. In general, the plasma in LEO is considered a high density, low energy plasma, while at GEO the plasma is low density but the energy is higher. A similar type of environment exists at the Moon as in GEO. The plasma environment in the Mars atmosphere is due to an interaction of the solar and galactic winds with the high concentration $\mathrm{CO}_{2}$ atmosphere and results in high concentrations of the charged particles $\mathrm{O}^{+}, \mathrm{O}_{2}^{+}, \mathrm{CO}_{2}^{+}$.

As the design lifetime of the spacecraft becomes longer, the resistance of the wiring insulation to the arc tracking in the space environment becomes more and more critical. Prolonged exposure to the space environmental effects may cause degradation to the insulation, which may not be exposed in single effect testing. Therefore, testing of the wiring samples to determine the effects of prolonged exposure to the multifactor stresses of the space environment must be considered.

Table 8. Lunar Particulate Radiation [24]

\begin{tabular}{|l|c|c|c|}
\hline \multicolumn{1}{|c|}{ Source } & $\begin{array}{c}\text { MeV/ } \\
\text { nucleon }\end{array}$ & $\begin{array}{c}\text { Proton Flux } \\
\left(\mathrm{cm}^{-2} \mathrm{sec}^{-1}\right)\end{array}$ & $\begin{array}{c}\text { Penetration } \\
\text { Depth }(\mathrm{cm})\end{array}$ \\
\hline Solar Wind & $10^{-3}$ & $10^{8}$ & $10^{-6}$ \\
SCR's & 1 to $10^{2}$ & $10^{2}$ & $10^{-3}$ to 1 \\
GCR's & $10^{2}$ to $10^{4}$ & 1 & 1 to $10^{3}$ \\
\hline
\end{tabular}




\section{CONCLUSIONS}

NASA's requirements in future manned and unmanned space activities will demand large amounts of electrical power in comparison to today's spacecraft. This will add to the complexity of the wiring systems, increasing the likelihood of electrical failures. A significant amount of information exists on the effects of an aircraft's operational environment on wiring insulation, arc track resistant materials, and wiring constructions. However, little data has been gathered on the effects of the various space environments on the arc tracking phenomena.

The wiring insulations for future NASA missions must be reliable and in particular resistant to arc tracking. Some of the current insulations have been tested and shown to arc track at potentials as low as 28 VDC. The Space Station Freedom power is distributed at potentials of 28 to $160 \mathrm{VDC}$, and thus there is a risk of arc tracking failure. Therefore the impact of the multistress environment of space on the electrical performance of the wiring insulations must be fully characterized. For example, the arc tracking phenomena under low pressure and microgravity conditions needs to be studied. Also, the insulating material's endurance when exposed to long term space environmental effects, such as temperature cycling, radiation, meteoroids and debris, etc., must be determined.

It is anticipated that through the NASA Wiring for Space Applications Program, in conjunction with the efforts of other US governmental laboratories, industry, and academia, a better understanding of arc tracking in wiring insulations will be achieved. The resulting database of information will help in the development of lightweight, safe, and reliable wiring systems with new wiring constructions which are resistant to arc tracking, and suitable for use in aerospace applications.

\section{ACKNOWLEDGMENT}

The work reported in this paper was performed under contract NAS3-25266 with the NASA Lewis Research Center. The authors would like to thank Dr. Daniel R. Mulville, Director of NASA Headquarters' Office of Safety and Mission Quality, Technical Standards Division for his continued support and guidance.

\section{BEEERENCES}

[1] Osman, T., "Space History," St. Martins Press, New York, 1983.

[2] Schulze, N.R., "NASA Wiring Program Plan," NASA Office for Safety and Mission Quality, May, 1990.

[3] Peterson, R.V., "Orbiter Kapton Wire Operational Requirements and Experience," Presented at the NASA Workshop on Wiring for Aerospace Applications, NASA Lewis Research Center, Cleveland, Ohio, July, 1991.

[4] Pedley, M.D., "Considerations in Using Kapton Wire Insulation in Shuttle Systems," NASA Johnson Space Center, August, 1988.

[5] Soloman, R., Woodford, L., Domalewski, S., "New Insulation Constructions For Aerospace Wiring Applications," WL-TR-91-4066, June, 1991.
[6] "Space Station Freedom Technical Performance Measurement Report - Weight, Power, and Ram," Space Station Freedom Electrical Power System Document EID 00375 - 18, August 19, 1991.

[7] McPeak, W., "Space Wiring Workshop Expendable Launch Vehicle Requirements," Presented at the NASA Workshop on Wiring for Aerospace Applications, NASA Lewis Research Center, Cleveland, Ohio, July, 1991.

[8] "STS Investigators Guide," NASA Marshall Space Flight Center, 1988 .

[9] Nicholson, L.S., "Space Shuttle System Payload Accommodations," NSTS 07700, Volume XIV, January, 1988.

[10] Bercaw, R.W., Cull, R.C., "Electrical System Options for Space Exploration," Presented at the 26th Intersociety Energy Conversion Engineering Conference, Boston, Massachusetts, August 4-9, 1991.

[11] Chetty, P.R.K., "Satellite Technology and Its Applications," Fairchild Space Company, Germantown, Maryland, 1991.

[12] Woosley, A.P., Smith, O.B., Nassen, H.S., "Skylab Technology Electrical Power System," Presented at the American Astronautical Society Twentieth Annual Meeting, Los Angeles, Califomia, August 20-22, 1974.

[13] "Carriers for In-Space Technology Experiments," NASA Goddard Space Flight Center, April, 1984.

[14] "Power Systems Analysis for the 90 Day Study," NASA Johnson Space Center, Houston TX, 1990.

[15] Petri, D.A., Cataldo, R.L., Bozek, J.M., "Power System Requirements and Definition for Lunar and Mars Outposts," Proceedings of the 25th Intersociety Energy Conversion Engineering Conference, Vol. 1, Aerospace Power Systems, Reno, Nevada, pp. 18-27, August 12-17, 1990.

[16] Chetty, P.R.K., "Satellite Technology and Its Applications - A Short Course", George Washington University Continuing Education Center, Washington D.C., 1991.

[17] Roth, T.E., "An Evaluation of the Pyrolytic and ArcDamage Properties of Polyimide Wire Insulation for LowVoltage Applications," TR-669-001, NASA Johnson Space Center, White Sands Test Facility, 1991.

[18] Stueber, T.J., "Kapton Pyrolysis on Space Station Freedom's Solar Array Flexible Current Carrier," Presented at the NASA Workshop on Wiring for Aerospace Applications, NASA Lewis Research Center, Cleveland, Ohio, July, 1991.

[19] General Dynamics Commercial Launch Services, Inc. "Mission Planners Guide for the Atlas Launch Vehicle Family," Presented at the Commercial Atlas ' 89 Users Conference, March, 1989. 
[20] Hill, T.J., "Space Station Freedom Primary Power Wiring Requirements," Presented at the NASA Workshop on Wiring for Aerospace Applications, NASA Lewis Research Center, Cleveland, Ohio, July, 1991.

[21] Banks, B.A., Rutledge, S.K., DeGroh, K.K., Auer, B.M., Mirtich, M.J., Gebauer, L., Hill, C.M., Lebed, R.F., "LDEF Spacecraft Ground Laboratory and Computational Modeling Implications on Space Station Freedom's Solar Array Materials and Surfaces Durability," NASA Lewis Research Center, Cleveland, Ohio, 1991.

[22] Harris, R.H., "Space Station Freedom Electrical Power System Interim Primary Power Cable Insulation Study," Rockwell Intemational Space Station Freedom Electrical Power System Cable/Connector Design, May, 1990.

[23] Agrawal, B.N., "Design of Geosynchronous Spacecraft," Prentice-Hall, 1986.

[24] Smith, R.E., West, G.S., "Space and Planetary Environment Criteria Guidelines for Use in Space Vehicle Development, 1982 Revision," NASA TM 82478, January, 1983.

[25] Kaplan, D., "Environment of Mars, 1988," NASA TM 100470, October, 1988.

[26] Wertz, J.R., Larson, W.J., "Space Mission Analysis and Design," Space Technology Library, Kluwer Academic Publishers, 1991.

[27] Makovec, R.J., "Polyimide (Kapton ${ }^{\otimes}$ ) Insulated Wire (MIL-W.81381) and the Space Station Freedom Program," NASA Lewis Research Center, December 4, 1989.

[28] Friedman, R., "Combustion and Fires in Low Gravity," Presented at the NASA Workshop on Wiring for Aerospace Applications, NASA Lewis Research Center, Cleveland, Ohio, July 23, 1991.

[29] Rauschenbach, H.S., "Solar Cell Array Design Handbook," JPL SP 43-38, October, 1976.

[30] Banks, B.A., Rutledge, S.K., "Low Earth Orbital Atomic Oxygen Simulation For Materials Durability Evaluation," Proceedings from Spacecraft Materials in Space Environment Symposium, CERT, Toulouse, France, September, 1988.

[31] Katzan, C.M., Edwards, J.L., "Lunar Dust Transport and Potential Interactions With Power System Components," NASA CR 4404, 1991.

[32] Purvis, C.K., Ferguson, D.C., Snyder, D.B., Grier, N.T., Staskus, J.V., Roche, J.C., "Environmental Interactions Considerations for Space Station and Solar Array Design," December, 1986.

[33] "Space Station Program Natural Environment Definition for Design," NASA SSP 30425 Basic, January, 1991.

[34] Gaustad, K.L., Gordon, L.B., Weber, J.R., "Electrical Transmission Lines for Use on the Lunar Surface," Presented at the NASA Workshop on Wiring for Aerospace Applications, NASA Lewis Research Center, Cleveland, Ohio, July 23, 1991.

[35] Purvis, C.K., Garrett, H.B., Whittlesey, A.C., Stevens, N.J., "Design Guidelines for Assessing and Controlling Spacecraft Charging Effects," NASA TP-2361, September, 1984.
[36] Dever, J., NASA Lewis Research Center, Personal Conversation, March, 1991.

[37] Hammoud, A.N., "Effects of High Energy Electron Radiation on Polypropylene Dielectric," PhD dissertation. The State University of New York at Buffalo, Buffalo, New York, 1987. 


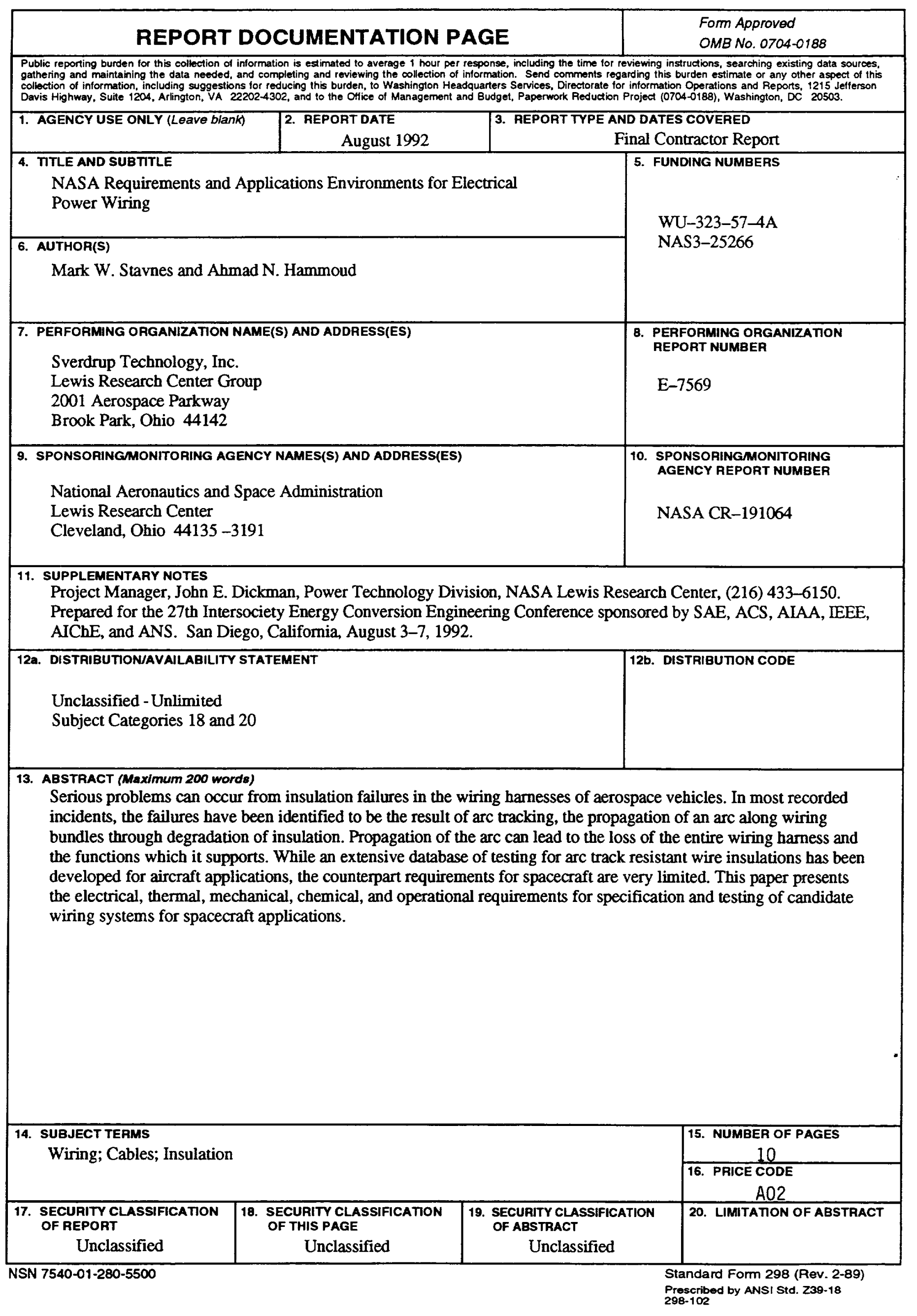


National Aeronautics and Space Administration

Lewis Research Center

Cleveland, Ohio 44135

Orifelel Bualnes:

Penainy for Privete Ues $\$ 300$
FOURTH CLASS MAIL

ADDRESS CORRECTION REQUESTED

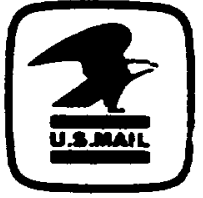

Posiage and Fees Paid National Aeronaulics and

Space Admınısiralıon

NASA 451 


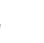

